\title{
Parameters of the center of pressure displacement on the saddle during hippotherapy on different surfaces
}

\author{
Fabiana M. Flores ${ }^{1}$, Frederico Dagnese ${ }^{1}$, Carlos B. Mota ${ }^{1,2}$,
} Fernando Copetti ${ }^{1,2}$

\begin{abstract}
Background: Hippotherapy uses horseback riding movements for therapeutic purposes. In addition to the horse's movement, the choice of equipment and types of floor are also useful in the intervention. The quantification of dynamic parameters that define the interaction of the surface of contact between horse and rider provides insight into how the type of floor surface variations act upon the subject's postural control. Objective: To test whether different types of surfaces promote changes in the amplitude (ACOP) and velocity (VCOP) of the center of pressure (COP) displacement during the rider's contact with the saddle on the horse's back. Method: Twenty two healthy adult male subjects with experience in riding were evaluated. The penetration resistances of asphalt, sand and grass surfaces were measured. The COP data were collected on the three surfaces using a pressure measurement mat. Results: ACOP values were higher in sand, followed by grass and asphalt, with significant differences between sand and asphalt (anteroposterior, $\mathrm{p}=0.042$; mediolateral, $\mathrm{p}=0.019)$. The ACOP and VCOP values were higher in the anteroposterior than in the mediolateral direction on all surfaces (ACOP, $p=0.001$; VCOP, $p=0.006$ ). The VCOP did not differ between the surfaces. Conclusion: Postural control, measured by the COP displacement, undergoes variations in its amplitude as a result of the type of floor surface. Therefore, these results reinforce the importance of the choice of floor surface when defining the strategy to be used during hippotherapy intervention.
\end{abstract}

Keywords: physical therapy; postural balance; hippotherapy; pressure.

\section{HOW TO CITE THIS ARTICLE}

Flores FM, Dagnese F, Mota CB, Copetti F. Parameters of the center of pressure displacement on the saddle during hippotherapy on different surfaces. Braz J Phys Ther. 2015 May-June; 19(3):211-217. http://dx.doi.org/10.1590/bjpt-rbf.2014.0090

\section{Introduction}

Hippotherapy uses the horse's gait as the mediator of a therapeutic effect obtained from the response to four factors involved in neuromuscular facilitation: integration of motor afferents; muscle activation, which triggers the activation of other muscles in a specific mobility chain; activation of the lumbar system as an essential exercise in its own function; and activation of muscle groups responsible for movements of the contralateral side of the body ${ }^{1}$. During horse riding, the movement of the horse's legs and pelvis in a rhythmic oscillation pattern provides motor and sensory inputs to the rider that are similar to pelvic movements in the human gait ${ }^{2}$.

Based on these principles, previous studies have investigated hippotherapy and have demonstrated its benefits in posture and balance for individuals presenting with post-stroke hemiparesis ${ }^{3,4}$, multiple sclerosis $^{5-7}$, Down syndrome ${ }^{8}$, brain paralysis ${ }^{9,10}$, and older age ${ }^{11}$. In addition, two studies have reported the dynamic parameters of the interaction between rider and horse in hippotherapy: one study showed direct relationships between the riding experience, contact pressure, and stability of the center of pressure (COP) movements ${ }^{1}$, while the other study showed that $\mathrm{COP}$ displacement was higher among individuals with cerebral palsy compared with those without this dysfunction ${ }^{12}$.

The assessment of the dynamic parameters that define the interaction between rider and horse on the contact surface is essential for evaluating empirical procedures that form the basis of clinical hippotherapy ${ }^{1}$. According to Clayton et al. ${ }^{12}, \mathrm{COP}$ is the point at which the total force transmitted through the saddle to the horse's back is active. The COP position is calculated on the basis of the magnitude and distribution of the forces applied to the pressure pad and allows the calculation of the amplitude of COP displacement (ACOP) and velocity of COP displacement (VCOP), which reflect

${ }^{1}$ Programa de Pós-graduação em Educação Física, Centro de Educação Física e Desportos, Universidade Federal de Santa Maria (UFSM), Santa Maria, 
the movements of the rider's torso. These parameters provide a basis for understanding the implications of the variations that can be created during horseback riding on the postural control of the riders.

One of the variations used in hippotherapy sessions to induce different responses in the rider is the variation of the surface type, for example between sand, asphalt, and grass ${ }^{7,13,14}$. Only one study ${ }^{14}$ has investigated the rider's pelvic mobility during horseback riding using distinct floor surfaces. The pelvic-tilt angle was measured in the frontal plane, corresponding to the upward and downward movements of the posterior-superior iliac spine during mounting on a pressure pad. This study indicated significant changes in the pelvic-tilt angle with changes in the type of surface on which the riding occurred.

To the best of our knowledge, no previous studies have addressed the effects of changes in common floor surface during hippotherapy on the oscillation parameters of COP. However, the differences in the shock amplitude and impact force generated by distinct floor surfaces during the contact of the horse's legs with the surface have already been demonstrated ${ }^{15}$ and indicate the importance of evaluating the effects of these changes on COP parameters. This strategy aims to help develop appropriate and specific hippotherapy programs on an individual basis through the control of the amount and type of sensory information.

Therefore, the aim of this study was to assess whether different floor surfaces could promote changes in the amplitude and velocity of COP displacement in healthy subjects as a result of the contact of riders with the saddle over the back of a walking horse. The study hypothesis was that differences in the resistance of each floor could promote changes in the horse's movement and, consequently, could change the demand for the rider's posture control, as measured by ACOP and VCOP.

\section{Method}

\section{Subjects}

The selection of the study participants was non-probabilistic and intentional. Following the commander's authorization, the riders from the Mounted Police Regiment were evaluated. This cross-sectional and observational study evaluated the 22 healthy male adults aged $30 \pm 7$ years with at least six months of experience in horseback riding and who practiced horseback riding at least three times a week, to take into account that Janura et al. ${ }^{1}$ indicated that the rider's experience level influenced the COP parameters.

The anthropometric characteristics ${ }^{16}$ evaluated were body weight $(77 \pm 11 \mathrm{~kg})$, height $(170 \pm 10 \mathrm{~cm})$, body mass index (BMI) $\left(26 \pm 3 \mathrm{~kg} / \mathrm{m}^{2}\right)$, trunk-cephalic height $(140 \pm 3 \mathrm{~cm})$, trochanteric height $(90 \pm 4 \mathrm{~cm})$, head perimeter $(58 \pm 3 \mathrm{~cm})$, neck perimeter $(39 \pm 2 \mathrm{~cm})$, shoulder perimeter $(117 \pm 6 \mathrm{~cm})$, chest perimeter $(99 \pm 6 \mathrm{~cm})$, abdominal perimeter $(89 \pm 8 \mathrm{~cm})$, hip perimeter $(102 \pm 5 \mathrm{~cm})$, thigh perimeter in the proximal region $(60 \pm 5 \mathrm{~cm})$, and leg perimeter $(37 \pm 3 \mathrm{~cm})$. The length of experience in horseback riding varied between 6 months and 22 years $(6.09 \pm 7.20$ years). The weekly and daily frequencies of horseback riding were $5.7 \pm 0.1$ days/week and $5.0 \pm 1.2$ hours/day, respectively. The project was approved by the Research Ethics Committee of the Universidade Federal de Santa Maria (UFSM) located in Santa Maria in the state of Rio Grande do Sul, Brazil, under protocol number 23081.013310/2011-06. All subjects were informed about the study procedures and signed an informed consent form.

\section{Floor surfaces tested}

The study consisted of three equal-sized equestrian areas with three distinct floor surfaces: sand, grass, and asphalt. These surfaces were selected because they reproduced conditions that are commonly used in hippotherapy. The cone index was used to obtain the penetration resistance of each surface. For this purpose, a Falker penetrometer (model PLG1020) with a metal rod and a type- 2 cone-shaped tip (12.83 $\mathrm{mm}$ in diameter) was used. The measurement consisted of introducing the penetrometer into the floor surface at a constant speed at depths between 0 and $100 \mathrm{~mm}$ from the surface. The asphalt was completely resistant to penetration based on the method used. For the other two floors, measurement was performed once a week during the study period. Three measurements of sand $\&$ grass surfaces were made daily yielding the same consistent resistance values during data collection $(\mathrm{p}=0.085$ and $\mathrm{p}=0.170$ for sand and grass, respectively). Figure 1 shows the mean values of resistance to penetration for sand and grass at depths between 0 and $100 \mathrm{~mm}$.

The characterization of the floor surface indicated that asphalt was resistant to penetration and that grass was more resistant than sand. However, after a depth of $80 \mathrm{~mm}$, the resistance of sand changed, possibly because the surface beneath consisted of gravel, which altered its resistance to penetration. 


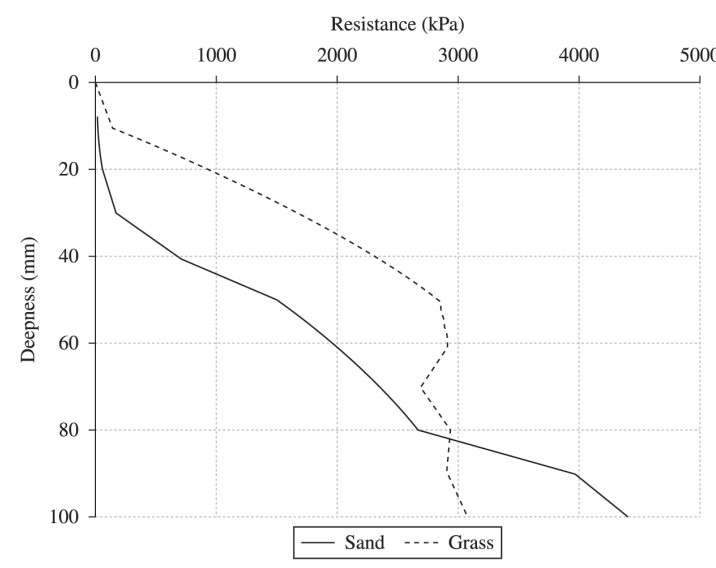

Figure 1. Profile of mean resistance versus ground depth values between 0 and $100 \mathrm{~mm}$ in the sand and grasssurfaces.

\section{Dynamometric evaluation}

To measure the contact pressure on the saddle, a portable pressure measurement system was used (CONFORMat ${ }^{\circledR}$, model 5330, Teckscan, Boston, USA), composed of a pad with 1,024 sensors arranged in 32 columns and 32 rows spaced $1.4732 \mathrm{~cm}$ apart, a sensitive area of $2.17 \mathrm{~cm}^{2}$, and an individual maximum measurement capacity of $0.0345 \mathrm{~N} / \mathrm{mm}^{2}$ (5 psi). Calibration of the system, previously to collect data, was performed according to the manufacturer's instructions, wherein each subject had his body weight taken and inputed into the database. The evaluation followed consisting of the rider remaining seated on the pad on a hard surface, with the feet unsupport, for a period of 90 seconds. The fixation area of the mat included the entire contact area of the rider's pelvis with the saddle surface. The subjects were instructed to remain seated throughout the test period to prevent the pad from moving over the saddle, which was ensured before each data collection.

Data were collected at a frequency of $100 \mathrm{~Hz}$. The system allowed the extraction of COP data and calculated the amplitude of COP displacement in the anteroposterior direction (ACOP $a p$ ) and mediolateral direction (ACOP $m l$ ), along with the velocity of COP displacement in the anterior-posterior direction (VCOP $a p$ ) and mediolateral direction (VCOP $m l$ ).

\section{Procedures}

Postural and anthropometric assessments which were later inputted into the database were performed on all subjects. The same horse was used throughout the study, with no specific breed, aged 5 years, height of withers of $154 \mathrm{~cm}$, and weight of $510 \mathrm{~kg}$. During the study, a veterinarian evaluated the horse, and its condition was healthy. The same English saddle composed of snaffle bridle, reins, and lead were used during data collection.

The rider's position during horse riding was the typical position, with the hands holding the reins, feet supported by the stirrups, and knees at a comfortable angle. The internal angle of the knees was measured using a goniometer; the mean value was $121.4 \pm 8.0$ degrees.

The horse was led by an experienced guide because in hippotherapy, the person sitting on the moving horse works to maintain their balance and posture while the horse is led by the guide ${ }^{17}$. This procedure was used to maintain similar travel speeds, as recommended by Dvořáková et al. ${ }^{18}$.

The horse's speed was initially assessed by observing and repeating the same stride. The distance traveled by the horse in 10 seconds was 10 meters, which corresponded to the interval estimated for data collection, with a frequency of nine strides during this period. On the basis of these values, the mean frequency was 54 strides $/ \mathrm{min}$, and the mean speed was $1.0 \mathrm{~m} / \mathrm{s}$. During data collection for each trial, a distance of 1 meter was marked before the beginning of the $10-\mathrm{m}$ path traveled by the horse to determine the place where the touch of the horse's right forelimb would indicate the art time for collection of dynamometric data. Similarly, a 1-meter distance was marked after the $10-\mathrm{m}$ path had been traveled by the horse to determine where the horse's right forelimb would touch the ground to complete the nine-stride cycle, and this criterion was used to ensure that each measurement was considered valid and to avoid variations $>10 \%$ of the speed of $1.0 \mathrm{~m} / \mathrm{s}$.

Prior to data collection using the pressure measurement pad, the rider on the horse was allowed to walk for 1 minute on each surface to allow time for adaptation. The dynamometric evaluation was initiated when the horse moving at the desired gait speed hit the marked area to start data collection. The system was manually activated, and data were collected over 10 seconds; the system was then automatically switched off. There were three valid repetitions on each floor surface. In only two subjects we had to repeat the test for the fourth times.

\section{Data analysis}

Data were acquired on the three different floor surfaces and were input into Microsoft Excel spreadsheets for data processing according to the protocol detailed 
by Schappo ${ }^{19}$ and Clayton et al. ${ }^{12}$. ACOPap and $\mathrm{ACOP} m l$ were calculated using the following equations: ACOP $a p=($ Ymax.1.4732 $)-($ Ymin.1.4732 $)$ and $\mathrm{ACOP} m l=(\mathrm{Xmax} .1 .4732)-(\mathrm{Xmin} .1 .4732)$, where Ymax and Ymin were the maximum and minimum anterior-posterior $(a p)$ values on the Y-axis, respectively, and $\mathrm{Xmax}$ and $\mathrm{Xmin}$ were the maximum and minimum mediolateral $(m l)$ values on the $\mathrm{X}$-axis.

The distances traveled by the COP in the ap and $m l$ direction (D) were calculated using the following equations: $\mathrm{D} a p(1.2) 2=|(\mathrm{Y} 2.1 .4732)-(\mathrm{Y} 1.1 .4732)|$ and Dml: (1.2) $2=|(\mathrm{X} 2.1 .4732)-(\mathrm{X} 1.1 .4732)|$, where Dap (1.2) $2(\mathrm{~cm})$ was the distance traveled by COP in absolute value between the first and second frames, totaling 1,000 frames; Y1 and Y2 were the initial and final ap values on the Y-axis, respectively; $\mathrm{Dml}$ (1.2) $2(\mathrm{~cm})$ was the distance traveled by COP in absolute value in the $m l$ direction between the first and the second frames, totaling 1,000 frames; and X1 and $\mathrm{X} 2$ were the initial and final $\mathrm{ml}$ values on the $\mathrm{X}$-axis, respectively. The total distance traveled by COP in the ap and $m l$ directions was the sum of the values of all frames.

To calculate VCOPap and VCOPml, the total distances traveled by COP in the $a p$ and $m l$ directions were used, respectively, divided by the time of acquisition of 1,000 frames.

\section{Statistical analysis}

The Shapiro-Wilk normality test was used to evaluate data normality. A logarithmic transformation was used to normalize the VCOPap and VCOP $m l$ data. Two multivariate analyses (multivariate analysis of variance-MANOVA) were performed on the three distinct floor surfaces (i.e. sand, grass, and asphalt). ACOPap, ACOP $m l$, VCOPap and VCOP $m l$ were the dependent variables. The post-hoc Bonferroni test was used, and the significance level was set at 5\%. Pearson's parametric correlation test was used to evaluate the correlation between the COP variables and the anthropometric characteristics. All analyses were performed using the software SPSS 14.0 (SPSS Inc., Chicago IL, USA).

\section{Results}

The ACOPap, ACOP $m l, \mathrm{VCOP} a p$ and VCOP $m l$ values on the three types of floor surfaces are shown in Table 1. The results of the MANOVA test indicated a difference between the floor surfaces, with Wilks' Lambda $=0.85, \mathrm{~F}(4.124)=2.61$, $\mathrm{p}<0.05$. The amplitudes of displacement in the $a p$ and $m l$ directions were higher on the sand, followed by grass and asphalt surfaces. However, significant differences were observed only between

Table 1. Means and standard deviations of the amplitude of center of pressure displacement in an anteroposterior direction (ACOPap), amplitude of center of pressure displacement in a medial - lateral direction (ACOP $m l)$, velocity of center of pressure displacement in an anteroposterior direction (VCOPap) and velocity of center of pressure displacement in a medial lateral direction (VCOPml) values for the three different floor surfaces.

\begin{tabular}{cccc}
\hline Variable & Sand & Grass & Asphalt \\
ACOP $a p(\mathrm{~cm})$ & $3.71(0.79)^{\mathrm{aA}}$ & $3.30(0.80)^{\mathrm{abA}}$ & $3.10(0.78)^{\mathrm{bA}}$ \\
ACOP $m l(\mathrm{~cm})$ & $2.81(0.52)^{\mathrm{aB}}$ & $2.66(0.48)^{\mathrm{abB}}$ & $2.38(0.43)^{\mathrm{bB}}$ \\
VCOP $a p(\mathrm{~cm} / \mathrm{s})$ & $6.21(1.91)^{\mathrm{cC}}$ & $5.95(1.92)^{\mathrm{cC}}$ & $5.89(1.73)^{\mathrm{cC}}$ \\
VCOP $m l(\mathrm{~cm} / \mathrm{s})$ & $5.19(1.31)^{\mathrm{cD}}$ & $5.01(1.10)^{\mathrm{cD}}$ & $4.88(1.08)^{\mathrm{cD}}$ \\
\hline
\end{tabular}

In the rows, the different lowercase letters indicate significant differences in ACOPap and ACOP $m l$ (shown by 'a' and 'b') and in VCOPap and VCOPml (shown by 'c' and 'd'). In the columns, the different uppercase letters indicate significant differences in ACOP $a p$ and $\mathrm{ACOP} m l$ (shown by 'A' and 'B') and in VCOP $a p$ and VCOP $m l$ (shown by 'C' and 'D').

Table 2. Correlations of the velocity of center of pressure displacement in an anteroposterior direction (VCOPap) and velocity of center of pressure displacement in a medial lateral direction (VCOP $m l$ )values on the three different types of floor surface with the anthropometric characteristics.

\begin{tabular}{|c|c|c|c|c|c|c|}
\hline Variables & $\underset{\left(\mathrm{kg} / \mathrm{m}^{2}\right)}{\mathrm{BMI}}$ & $\begin{array}{c}\text { Body weight } \\
\text { (kg) }\end{array}$ & $\begin{array}{c}\text { Abdomen } \\
\text { Perimeter }(\mathrm{cm})\end{array}$ & $\begin{array}{l}\text { Hip Perimeter } \\
\text { (cm) }\end{array}$ & $\begin{array}{c}\text { Thigh } \\
\text { Perimeter }(\mathrm{cm})\end{array}$ & $\begin{array}{c}\text { Leg } \\
\text { Perimeter (cm) }\end{array}$ \\
\hline $\operatorname{VCOP} m l\left(\mathrm{~cm} / \mathrm{s}^{2}\right)$ sand & -0.293 & -0.272 & $-0.440^{*}$ & -0.374 & $-0.426^{*}$ & -0.309 \\
\hline $\operatorname{VCOP} m l\left(\mathrm{~cm} / \mathrm{s}^{2}\right)$ grass & $-0.499 *$ & $-0.495^{*}$ & $-0.506^{*}$ & $-0.577 * *$ & $-0.468^{*}$ & $-0.556^{* *}$ \\
\hline $\mathrm{VCOP} m l\left(\mathrm{~cm} / \mathrm{s}^{2}\right)$ asphalt & $-0.437 *$ & $-0.480^{*}$ & $-0.510^{*}$ & $-0.595^{* *}$ & $-0.505^{*}$ & $-0.524^{*}$ \\
\hline VCOPap $\left(\mathrm{cm} / \mathrm{s}^{2}\right)$ sand & $-0.550 * *$ & $-0.464 *$ & $-0.607 * *$ & $-0.470^{*}$ & $-0.494 *$ & $-0.562 * *$ \\
\hline VCOPap $\left(\mathrm{cm} / \mathrm{s}^{2}\right)$ grass & $-0.423^{*}$ & -0.291 & $-0.479^{*}$ & -0.388 & -0.358 & $-0.438^{*}$ \\
\hline VCOPap $\left(\mathrm{cm} / \mathrm{s}^{2}\right)$ asphalt & $-0.457 *$ & -0.346 & $-0.545^{* *}$ & $-0.436^{*}$ & -0.382 & $-0.428^{*}$ \\
\hline
\end{tabular}

*Significant correlation at $5 \%$. * Significant correlation at $1 \%$. 
sand and asphalt surfaces ( $\mathrm{p}=0.042$ and $\mathrm{p}=0.019$ in the $a p$ and $m l$ directions, respectively). The MANOVA test results indicated no difference in VCOP among the floor surfaces, with Wilks' Lambda $=0.99$, $\mathrm{F}(4.124)=0.21, \mathrm{p}>0.05$.

The ACOP and VCOP values were significantly higher in the ap direction compared with the $m l$ direction on all floor surfaces $(\mathrm{p}=0.001$ and $\mathrm{p}=0.006$ for $\mathrm{ACOP}$ and VCOP, respectively). No correlation was observed between the anthropometric characteristics evaluated and ACOP ap and ACOP $m l$. A negative correlation was observed between the anthropometric characteristics and the VCOPap and VCOPml values (Table 2).

\section{- Discussion}

Anthropometric measurements and pressure measurement systems have been shown to be effective in biomechanical studies using horses ${ }^{20}$. Previous studies with horses have evaluated the COP parameters and the force acting upon the horse's back using an apparatus positioned under the saddle, in conditions of distinct strides ${ }^{21}$, for the calculation of the stride cycles $^{22}$ and for the evaluation of different riding positions ${ }^{23}$. However, the present study aimed to evaluate the effect of the transfer of movement from horse to rider; therefore, the measurement pad was positioned over the saddle, as also reported by Janura et al. ${ }^{1}$ in a hippotherapy study.

The results of the present study demonstrated that ACOP differed among the floor surfaces evaluated. However, VCOP did not change with changes in the floor surface. The comparison between ACOP and VCOP in the ap and $m l$ directions indicates that these parameters were significantly different and were higher in the ap direction. In addition, ACOP was not associated with the anthropometric characteristics, whereas VCOP was associated negatively with body weight and the perimeters of the abdomen, hip, thigh, and leg.

Furthermore, ACOP values were higher on sand, intermediate on grass, and low on asphalt. However, the only significant difference occurred between asphalt and sand. The results of the cone index indicated that of the 3 surfaces tested, sand was least resistant, grass was in the middle for penetration resistance, and asphalt was the floor surface completely resistant to penetration. These results indicate the increased penetration of the horse's legs in the sand and explain the higher ACOP values among individuals on this floor surface in both the ap and $m l$ directions. The properties of the floor surface were also evaluated by Chateau et al. ${ }^{15}$, who observed that sand, compared with grass and asphalt, decreased the shock amplitude and the impact force in the vertical and horizontal directions when the horse's legs touched the ground during trotting.

In addition, ACOP values in the ap and $m l$ directions differed and were larger in the ap direction. These findings on horse riding corroborate those found by Janura et al. ${ }^{1}$, wherein the measurement pad was placed over the saddle (i.e. the interaction was between the saddle and the rider), and those of Jeffcott et al. ${ }^{20}$, wherein the pad was placed underneath the saddle (i.e. the interaction was between the horse's back and the saddle). Janura et al. ${ }^{1}$ pointed out that these findings might be related to the fact that the natural direction of the horse's gait was in the ap direction. Although Shumway-Cook and Wollacott ${ }^{24}$ did not address the horse-human interaction, they indicated that the degrees of freedom of movement of the ankle and hip joints and the trunk mobility were higher in the ap direction than in the $m l$ direction in both static and dynamic conditions, which could explain the similarity of the results found in these studies.

The results of Clayton et al. ${ }^{12}$ corroborate our data and indicate an ACOP value higher in the ap direction than in the $m l$ direction in healthy subjects during horseback riding. In subjects with cerebral palsy, the ACOP values in the ap and $m l$ directions were even higher, and these results were attributed to the poor control of trunk stability. In their study, the measurement pad was positioned under the saddle.

The degree of rider experience influenced ACOP. In this respect, Janura et al. ${ }^{1}$ found that apprentice riders had decreased contact area and increased ACOP on the asphalt surface compared with experienced riders. These characteristics were associated with physical and mental strain, along with physical instability while the beginner rider had not adapted to the new motor activity. However, it was observed that beginners, after five sessions, had favorable adjustments associated with increased contact area and decreased ACOP, indicating increased body relaxation and trunk stability. In the present study, the subjects who were evaluated rode regularly and were therefore considered experienced and had adapted to the riding activity. Therefore, the differences observed among the different surfaces in terms of resistance were sufficient to cause changes in ACOP, particularly between the sand and asphalt surfaces. 
Although the different floor surfaces significantly affected ACOP, these surfaces did not affect VCOP when healthy individuals experienced in horse riding were subjected to the task of riding while walking horse. This result allowed the authors to indirectly evaluate the neuromuscular control of subjects ${ }^{13}$, who had good pelvic mobility and postural stability in the face of disturbances in the horse's movement induced by the type of floor surface. This control, coupled with the effect of learning, allowed more experienced riders to decrease COP movement, possibly through pre-tension/pre-activation of muscles in anticipation of the rhythmic movements of the horse ${ }^{25}$. Therefore, the riders experience seems to be more associated with the capacity to control VCOP in relation to ACOP in the conditions proposed in this study.

The VCOP values in the $a p$ and $m l$ directions differed and were higher in the ap direction. Our results corroborate with those of Clayton et al. ${ }^{12}$, in which the pressure-measuring pad was positioned under the saddle, and VCOPap was higher than VCOPml in both healthy subjects and those with cerebral palsy. Furthermore, these authors demonstrated that the VCOP $m l$ of individuals with cerebral palsy during horseback riding was higher than that of individuals without this dysfunction. This finding is consistent with that of the study of Jeffcott et al. ${ }^{20}$, in which large deviations in the $m l$ direction occurred when the rider had poor stability and balance during the horse's movement.

In the present study, no significant correlations were detected between ACOP and the anthropometric characteristics, possibly because the ACOP data represented the variabilities caused by changes in the type of floor surface. In contrast, VCOP was negatively correlated with the anthropometric characteristics, so subjects with larger perimeters of the abdomen, hip, thigh, and leg; higher BMI; and higher body weight exhibited lower VCOP values. This finding may indicate increased inertia in response to the horse's movements. The anthropometric characteristics of trunk length and height did not correlate with VCOP.

Some important limitations of this study should be considered. The study evaluated the behavior that occurred during a 10 -second period with a frequency of nine strides during this time interval but did not evaluate this behavior per stride cycle. This evaluation would be possible with the use of a synchronization system that allowed the assessment of the stride phases of the horse.
With respect to the evaluation method used, it was practical and consistent for the investigation of empirical procedures used in hippotherapy. Therefore, other studies that could evaluate the different conditions used in the practice of hippotherapy, including the use of materials such as pads, a saddle, and stirrup support for the feet or the type of horse gait, are important for understanding the isolated effects of each of these variables on the COP parameters.

The results of this study are the first step of an assessment aimed at determining the changes in $\mathrm{COP}$ parameters during the horse-saddle-rider interaction as a function of variations in types of floor surface. Considering that the objective was to assess the effect of environmental changes under conditions used in hippotherapy to determine reference values, healthy subjects were used in the evaluation; therefore, clinical findings were not presented. However, these results demonstrate the importance of considering the type of floor surface when defining the strategies to be used during such interventions.

\section{References}

1. Janura M, Peham C, Dvořáková T, Elfmark M. An assessment of the pressure distribution exerted by a rider on the back of a horse during hippotherapy. Hum Mov Sci. 2009;28(3):387-93. http://dx.doi.org/10.1016/j.humov.2009.04.001. PMid:19406498

2. Uchiyama H, Ohtani N, Ohta M. Three-dimensional analysis of horse and human gaits in therapeutic riding. Appl Anim Behav Sci. 2011;135(4):271-6. http://dx.doi.org/10.1016/j. applanim.2011.10.024.

3. Beinotti F, Correia N, Christofoletti G, Borges G. Use of hippotherapy in gait training for hemiparetic post-stroke. Arq Neuropsiquiatr. 2010;68(6):908-13. http://dx.doi. org/10.1590/S0004-282X2010000600015. PMid:21243251

4. Lee CW, Kim SG, Yong MS. Effects of hippotherapy on recovery of gait and balance ability in patients with stroke. J Phys Ther Sci. 2014;26(2):309-11. http://dx.doi.org/10.1589/ jpts.26.309. PMid:24648655

5. Hammer A, Nilsagård Y, Forsberg A, Pepa H, Skargren E, Oberg B. Evaluation of therapeutic riding (Sweden)/ hippotherapy (United States). A single-subject experimental design study replicated in eleven patients with multiple sclerosis. Physiother Theory Pract. 2005;21(1):51-77. http:// dx.doi.org/10.1080/09593980590911525. PMid:16385943

6. Silkwood-Sherer D, Warmbier H. Effects of hippotherapy on postural stability, in persons with Multiple Sclerosis: a pilot study. J Neurol Phys Ther. 2007;31(2):77-84. http:// dx.doi.org/10.1097/NPT.0b013e31806769f7. PMid:17558361

7. Menezes KM, Copetti F, Wiest MJ, Trevisan CM, Silveira AF. Effect of hippotherapy on a postural stability of patients with multiple sclerosis: a preliminary study. Fisioter Pesqui. 2013;20(1):43-9. http://dx.doi.org/10.1590/ S1809-29502013000100008. 
8. Copetti F, Mota CB, Graup S, Menezes KM, Venturini EB. Angular kinematics of the gait of children with Down's syndrome after intervention with hippotherapy. Rev Bras Fisioter. 2007;11(6):503-7. http://dx.doi.org/10.1590/ S1413-35552007000600013.

9. Kwon JY, Chang HJ, Lee JY, Ha Y, Lee PK, Kim YH. Effects of hippotherapy on gait parameters in children with bilateral spastic cerebral palsy. Arch Phys Med Rehabil. 2011;92(5):774-9. http://dx.doi.org/10.1016/j.apmr.2010.11.031. PMid:21530725

10. Yokoyama M, Kaname T, Tabata M, Hotta K, Shimizu R, Kamiya K, et al. Hippotherapy to improve hypertonia caused by an autonomic imbalance in children with spastic cerebral palsy. Kitasato Med J. 2013;43:67-73.

11. Araújo TB, Oliveira RJ, Martins WR, Moura Pereira M, Copetti F, Safons MP. Effects of hippotherapy on mobility, strength and balance in elderly. Arch Gerontol Geriatr. 2013;56(3):478-81. http://dx.doi.org/10.1016/j. archger.2012.12.007. PMid:23290005

12. Clayton HM, Kaiser LJ, de Pue B, Kaiser L. Center-ofpressure movements during equine-assisted activities. Am J Occup Ther. 2011;65(2):211-6. http://dx.doi.org/10.5014/ ajot.2011.000851. PMid:21476369

13. Kim SG, Lee CW. The effects of hippotherapy on elderly persons' static balance and gait. J Phys Ther Sci. 2014;26(1):257. http://dx.doi.org/10.1589/jpts.26.25. PMid:24567669

14. Ioris MN, Macedo LB. Análise da mobilidade pélvica do cavaleiro provocada pela andadura ao passo do cavalo em terrenos variados. [Analysis of the pelvic mobility in horse riders caused by the horse's gait in varied terrains.]. Arquivos Brasileiros de Paralisia Cerebral. 2006;2(5):26-30.

15. Chateau H, Holden L, Robin D, Falala S, Pourcelot P, Estoup $\mathrm{P}$, et al. Biomechanical analysis of hoof landing and stride parameters in harness trotter horses running on different tracks of a sand beach (from wet to dry) and on an asphalt road. Equine Vet J Suppl. 2010;42(38):488-95. http://dx.doi. org/10.1111/j.2042-3306.2010.00277.x. PMid:21059050

16. Petroski EL. Antropometria: técnicas e padronizações. $2^{\mathrm{a}}$ ed. Porto Alegre: E. L. Petroski; 2003.

17. Svoboda Z, Dvoř́áková T, Janura M. Does a rider influence a horse's movement in hippotherapy? Acta Univ Palacki Olomuc. 2011;41(4):37-41.

18. Dvořáková T, Janura M, Svoboda Z, Elfmark M. The influence of the leader on a movement of a horse in walking during repeated hippotherapy sessions. Acta Univ Palacki Olomuc. 2009;39(3):43-50.

19. Schappo EW. Análise do controle postural de crianças normais e portadoras de paralisia cerebral hemiplégica pelo sistema de mensuração de pressão Clinseat da Tekascan ${ }^{\circledR}$ [monografia]. São Paulo: Universidade de São Paulo; 2003.

20. Jeffcott LB, Holmes MA, Townsend HGG. Validity of saddle pressure measurements using force-sensing array technology—preliminary studies. Vet J. 1999;158(2):113-9. http://dx.doi.org/10.1053/tvj1.1998.0334. PMid:10489267

21. Fruehwirth B, Peham C, Scheidl M, Schobesberger H. Evaluation of pressure distribution under an English saddle at walk, trot and canter. Equine Vet J. 2004;36(8):754-7. http://dx.doi.org/10.2746/0425164044848235. PMid:15656510

22. Von Peinen K, Wiestner T, Bogisch S, Roepstorff L, Van Weeren PR, Weishaupt MA. Relationship between the forces acting on the horse's back and the movements of rider and horse while walking on a treadmill. Equine Vet J. 2009;41(3):285-91. http://dx.doi.org/10.2746/042516409X397136. PMid:19469237

23. Peham C, Kotschwar AB, Borkenhagen B, Kuhnke S, Molsner J, Baltacis A. A comparison of forces acting on the horse's back and the stability of the rider's seat in different positions at the trot. Vet J. 2010;184(1):56-9. http://dx.doi. org/10.1016/j.tvj1.2009.04.007. PMid:19428275

24. Shumway-Cook A, Woollacott MH. Controle motor: teoria e aplicações práticas. $2^{\mathrm{a}}$ ed. São Paulo: Manole; 2003.

25. Terada K, Mullineaux DR, Lanovaz J, Kato K, Clayton HM. Electromyographic analysis of a rider's muscles at trot. Equine and Comparative Exercise Physiology. 2004;1(3):1938. http://dx.doi.org/10.1079/ECP200420.

\section{Correspondence}

\section{Fabiana Moraes Flores}

Universidade Federal de Santa Maria

Centro de Educação Física e Desportos

Avenida Roraima, 1.000, Cidade Universitária, Prédio 51, sala 1025, Camobi

CEP 97105-900, Santa Maria, RS, Brasil

e-mail: fabiana.mf@hotmail.com 